\title{
PENSAMENTOS AMEFRICANOS CONTRA O DÉFICIT DECOLONIAL EM
}

WALTER MIGNOLO ${ }^{1}$

Amefrican thoughts against the decolonial deficit in Walter Mignolo

\section{ALCÂNTARA, Débora Menezes²}

Resumo: 0 objetivo deste trabalho é apresentar, por um lado, uma leitura crítica de determinadas concepções fundantes das produções acadêmicas do pensamento decolonial, as ideias de paradigma outro e pensamento fronteiriço, assim como a forma em que a ideia de modernidade é por elas concebida. Com isso, procuramos advertir para uma tendência a um déficit decolonial na elaboração dessas concepções que possa incidir de forma enfraquecedora sobre o próprio projeto decolonial, que é a libertação. Por outro lado, partindo da crítica a tais contradições presentes no pensamento decolonial, procuramos argumentar sobre a potência decolonizadora em categorias forjadas nos pensamentos de intelectuais afrolatinoamericanas, a exemplo de Lélia Gonzalez e Beatriz Nascimento; categorias, estas, que perfazem um caminho reflexivo e ativo, alternativo a determinadas proposições do pensamento decolonial e que merecem ser retomadas e (re)introduzidas de forma mais significativa nos debates sobre projetos intelectuais emancipatórios da região. As reflexões aqui expostas se deram através de uma leitura comparada de autores inscritos na vocalização do "colonizado" e do tensionamento entre suas ideias e expressões epistêmicas.

Palavras-chave: Pensamento decolonial. Modernidade. Ação. Libertação.

Abstract: The goal of this paper is to present, on the one hand, a critical reading of certain founding conceptions of the academic production of decolonial thought, the ideas of another paradigm and border thinking, as well as the way the idea of modernity is conceived by them. Thus, we look to warn about a tendency of decolonial deficit in the elaboration of these conceptions that might weaken the decolonial project itself, which is liberation. On the other hand, starting from the critique to the present contradictions in decolonial thought, we look to discuss the decolonizing power of categories created by the thoughts of Afro-Latin Americans, such as Lélia Gonzalez and Beatriz Nascimento; categories which develop a reflexive and active path, alternative to certain propositions in decolonial thinking and that deserve to be taken up again and (re)introduced in a more meaningful way in the debates on emancipatory intellectual projects of the region. The reflections exposed here were done through a comparative reading of authors inscribed in the vocalization of the "colonized" and the tension between their ideas and epistemic expressions.

Keywords: Decolonial thought. Modernity. Action. Liberation.

\footnotetext{
${ }^{1}$ Recebido em: 15 mai. 2018. Aceito em: 18 set. 2018.

${ }^{2}$ Doutoranda em Ciência Política pela Universidade Federal de Minas Gerais (UFMG) e membro do Centro de Estudos Republicanos Brasileiros (Cerbrás) da UFMG. E-mail: alcdebora@gmail.com.
} 


\section{Introdução}

Há duas concepções importantes que integram as produções acadêmicas do movimento epistemológico decolonial, introduzidas por Walter Mignolo (2003, 2008), que merecem uma leitura crítica que aponte um caminho mais coerente com o projeto decolonial: um paradigma outro e pensamento fronteiriço. A primeira concepção seria um "paradigma libertador", de emancipação do oprimido da clausura da "modernidade"; a segunda, uma espécie de "categoria multivalente" (política, social, cultural), onde residiria a potência geradora do paradigma outro, que genuinamente teria um papel de ruptura e de negação do projeto "moderno", como defende o autor.

Nesse texto, pretendemos apresentar algumas contradições e vazios nessas concepções como um alerta para um possível déficit em que futuras reflexões possam incorrer ao se basearem na matriz de pensamento decolonial. Referimo-nos ao déficit decolonial, que está relacionado às incongruências de determinados caminhos reflexivos, os quais, em vez de convergir para a libertação, acabariam promovendo o apagamento das lutas decolonizadoras, por construir caminhos caros à ação política.

Destacamos em seguida algumas categorias forjadas nos pensamentos das intelectuais afrolatinoamericanas Lélia Gonzalez e Beatriz Nascimento: respectivamente a categoria político-cultural de amefricanidade e a categoria político-histórica de quilombo, as quais costuram um caminho reflexivo e ativo, alternativo a determinadas proposições do pensamento decolonial e cujo caráter decolonizador consegue visibilizar as lutas pela libertação em suas mais distintas performances, sem subsumir a potência de ação política a elas inerentes. Julgamos que essas concepções são expressões epistêmicas urgentes para os projetos intelectuais emancipatórios da região.

\section{A Diferença Colonial como Lugar de Enunciação}

Sendo um dos precursores do conjunto de ideias que integram o debate sobre modernidade/colonialidade, Walter Mignolo inscreve suas concepções numa crítica radical ao paradigma moderno, a qual recusa a ideia de que a América Latina chegou à pós-colonialidade com o fim da administração colonial. 0 autor toma como referência a 
dimensão geocultural, para além das leituras geo-históricas e geoeconômicas do sistemamundo moderno (Warllenstein, 1979). 0 movimento epistemológico decolonial, do qual o autor faz parte, discorre sobre a ideia de que padrões que se configuraram nas relações de poder em torno dos séculos XV e XVI ainda persistem na atualidade, numa contínua reprodução, lastreando, no presente, o "projeto de civilização neoliberal” (Mignolo, 2003, p. 19). Tais padrões culminam na concepção de colonialidade do poder, elaborada pelo teórico político peruano Aníbal Quijano, no início da década de 1990; concepção, esta, precedida pela ideia de colonialismo interno, de Pablo Gonzalez Casanova, nas décadas de 1960 e 1970. Diferentemente da ideia de Casanova, a concepção de colonialidade do poder rompe com a modernidade como Totalidade. Já nascida de uma ideia de exterioridade, nos termos de Dussel ${ }^{3}$, a concepção de colonialidade do poder vai ganhando maturidade e passa a evocar a raça como princípio organizador do capitalismo e das relações de poder, sendo, assim, interpretada como um dos eixos estruturadores do padrão de poder inaugural da modernidade.

A colonialidade do poder é assumido por Mignolo como “a força motriz que constituiu, transformou e continua reproduzindo a diferença imperial e a diferença colonial" (Mignolo, 2003, p. 36) - a primeira, consistindo um "processo intra-hierárquico dentro dos próprios impérios capitalistas, ocidentais e cristãos, como, por exemplo, a constituição do Sul da Europa - hoje também partícipe da ideia sociológica de Sul Global” (Ballestrin, 2013, p.102); a segunda, consistindo a "lógica de classificação e hierarquização das pessoas no planeta", por suas línguas, suas religiões, suas nacionalidades, sua cor de pele (Mignolo, 2000, p. 43), seus gêneros, suas sexualidades, etc, ou seja, um constructo que define a alteridade dos subalternizados, conjurando padrões de dominação.

Se a diferença colonial é um mecanismo de dominação que transforma as diferenças em valores e hierarquias e é constructo da colonialidade do poder, é também

\footnotetext{
3 Dussel refuta a narrativa "ilustrada" sobre o processo de origem da modernidade, julgando-a uma construção "intra-europeia, eurocêntrica, autocentrada, ideológica, feita desde a centralidade do Norte da Europa e a partir do século XVIII e que foi imposta até os nossos dias" (Dussel, 2015, p. 13) e propõe a ideia de que a Modernidade nasce a partir da implantação do "sistema-mundo", quando os impérios português e espanhol, ainda no final do século XV, se expandem a partir do Atlântico. Ou seja, o autor localiza a modernidade como um evento inextricavelmente relacionado ao colonialismo, mas também como uma totalidade geradora de um Outro, a qual nega este Outro ao mesmo tempo que o inventa. Existe, portanto, nos termos de Dussel, uma exterioridade negada; uma exterioriudade em relação à totalidade moderna.
} 
nela mesma onde a colonialidade do poder se articula. Por outro lado, a diferença colonial é ainda o lugar próprio da "ferida colonial", no sentido fanoniano, evocado por Mignolo para afirmar que é também da diferença colonial que insurge o pensamento fronteiriço dos "deserdados", a principal força acionadora, na visão do autor, de um paradigma outro, disruptivo em relação à autonarrativa moderna.

A diferença colonial, desta forma, é assumida por Mignolo como um "mapa" onde os lugares de enunciação, tanto das forças operadoras da colonialidade do poder, quanto da insurgência de um pensamento que rompe com os padrões da modernidade, estão dicotomicamente demarcados.

Atentar à ideia de diferença colonial articulada por Mignolo, portanto, é um passo interessante para que sejam flagradas algumas implicações que sua concepção de pensamento fronteiriço tem sobre o projeto decolonial.

\section{Déficit Decolonial do Pensamento Fronteiriço}

O pensamento fronteiriço, de acordo com Mignolo, insurge a partir do século XVI, "com a invenção da América", e tem sua continuidade com a história do capitalismo e "com a reprodução da lógica da colonialidade e da modernidade como ponto de chegada da civilização mundial” (Mignolo, 2003, p. 28). A nebulosidade dessa concepção se aprofunda quando o autor faz distinção entre "pensamento fronteiriço forte" e "pensamento fronteiriço fraco". O pensamento fronteiriço forte somente encontraria seu gatilho "na dor" e "na fúria da fratura das histórias" dos "deserdados", "de suas memórias, de suas subjetividades, de sua biografia" (2003, p. 28), num sentido mesmo de "ferida colonial" apontada por Fanon $(2005,2008)$. Ou seja, a diferença colonial seria o único locus de enunciação legitimamente capaz de acionar um "pensamento fronteiriço forte" (Mignolo, 2003, p. 28).

O pensamento fronteiriço fraco, por outro lado, "possível" e, inclusive, "necessário", de acordo com o autor, teria sua emergência, não da dor ou da fúria dos deserdados mesmos, "mas de quem, não sendo deserdados, toma a perspectiva destes" (2003, p. 28). Para justificar essa classificação hierarquizada, Mignolo afirma que, na geopolítica do 
conhecimento, a mesma perspectiva pode ser assumida a partir de lugares epistêmicos de enunciação distintos (p. 28).

Um dos problemas identificados é a atribuição ingênua de uma virtuosidade aos sujeitos potenciais do pensamento fronteiriço. Grosfoguel (2013) alerta para os riscos dessa "celebração" empreendida por Mignolo "de qualquer coisa que venha do lado dos subalternos, quando sabemos que historicamente o sistema tem sido exitoso porque tem logrado que os que estão socialmente abaixo pensem epistemicamente como os de cima" (Grosfoguel, 2013, p. 44). Para o autor, é importante diferenciar a "localização epistêmica" da "localização social". No entanto, segundo Grosfoguel, Mignolo produz um "reducionismo" e um "essencialismo grosseiro", ao derivar, de forma simplista, a posição epistêmica de um sujeito de sua localização social, incorrendo ao equívoco, inclusive, de "reduzir a localização social" à "localização geográfica" (2003, p. 44).

O pensamento fronteiriço, como estabelece Mignolo, põe em questão a lógica eurocêntrica e dominante ao "fazer visíveis outras lógicas e maneiras de pensar diferentemente" (Walsh, 2005, p. 29), abrindo espaço para a expressão de outras perspectivas de conhecimento e saberes, mas não escapa ao que chamaremos aqui de déficit decolonial.

Ao comparar a noção de pensamento outro do autor árabe-islâmico Abdelkebir Khatibi com a de pensamento fronteiriço, Catherine Walsh (2005) expõe algumas insuficiências da elaboração conceitual de Mignolo em relação ao projeto decolonial. Enquanto o pensamento fronteiriço se dicotomiza com o pensamento dominante, "mantendo-o como referente, sujeitando-o ao questionamento e infectando-o com outras histórias e modos de pensar", sem sair do regime do antagonismo, o pensamento outro de Khatibi se constrói "casa adentro", explorando as "mediações ou negociações inter ou intra-subalternos" (Walsh, 2005, p. 29).

Tendo em vista a rede complexa de relações de poder inerentes à diversidade de pensamentos, a autora demarca que existe uma multiplicidade de fronteiras para além da fronteira que demarca a modernidade e a colonialidade e ainda enfatiza que a ideia de pensamento fronteiriço elaborada por Mignolo "não muda radicalmente a eurocentricidade, tampouco a subalternização", sendo insuficiente para a construir "uma 
nova condição social do conhecimento ou um novo poder social, ou para alcançar a decolonialidade do poder, saber e ser" (p. 29).

Retomando a comparação que Walsh faz entre o pensamento fronteiriço, de Mignolo, e o pensamento outro, de Khatibi, é possível reconhecer ainda um vazio deixado pelo primeiro: um esteio caro e minguado para a ação. Diferentemente de Mignolo, Khatibi parece sorver de forma mais coerente o sentido radical de luta fanoniana, erigida da ferida colonial, atribuindo ao pensamento, a possibilidade real de "descolonializar-se", justamente por não abandonar a dimensão da estratégia: "uma estratégia sem sistema fechado", que se assuma como "uma construção de um jogo do pensar e do político, que ganha terreno silenciosamente sobre seus desfalecimentos e seus sofrimentos" (apud Walsh, 2005, p. 22).

A proposta de Walsh, diferentemente da de Mignolo, dribla de forma mais sagaz os riscos dos essencialismos e ganha uma dimensão política que é fundamental para o reconhecimento da opressão e da luta nas relações entre os diversos modos de pensar, inclusive os "pensamentos-outros". Desta forma, o sentido de "fronteiras" acaba perdendo força para a ideia de interculturalização crítica, que seria, na proposta de Walsh, uma consequência do posicionamento crítico fronteiriço. 0 "posicionar estratégico" não teria como principal fim pluralizar ou abrir o pensamento eurocêntrico e dominante, mas "construir vínculos estratégicos entre grupos e conhecimentos subalternizados", para que se possa levar a cabo "a estratégia-outra a que Khatibi (2001) tem se referido e que aponta uma transformação crítica e radical" (Walsh, 2005, p. 30), cujo esteio viabilizador é inexoravelmente a luta.

\section{Paradigma Outro e o "Encapsulamento" da Pluriversidade}

Da mesma forma que a díade modernidade/colonialidade é fulcral para o pensamento fronteiriço, o paradigma outro proposto por Mignolo não poderia deixar de ser demarcado pela dicotomização, já que é a própria "expressão que convoca diferentes projetos da modernidade/colonialidade unidos pelo pensamento fronteiriço" (Mignolo, 2003, p. 50). 
O paradigma outro seria, então, uma espécie de conquista ontológica dos "deserdados", cujo ponto de partida residiria no pensamento fronteiriço, do lado da dor da experiência colonial no mapa que separa opressores e oprimidos. 0 paradigma outro seria genuinamente "um paradigma do sul", como afirma o próprio Mignolo (2003, p. 53); um paradigma onde os anseios não buscariam superar o paradigma hegemônico, mas coexistir em conflito com ele. 0 sentido desse paradigma utopístico se evidenciaria na constatação do "esgotamento do projeto da modernidade" (p. 20).

Insurgido das vozes subalternizadas da colonialidade, o paradigma outro seria, então, um paradigma de ruptura e não estaria para uma outra "universalidade abstrata", monotópica, típica do paradigma eurocêntrico, mas para a "diversalidade", ou ainda, para a "diversidade como projeto universal" (p. 20), permeada de pensamentos pluriversais (p. 52). Mignolo preza, então, a ideia de uma "cosmopolitismo crítico" como alternativa à hegemônica globalização neoliberal, onde sobrevive e se reproduz a modernidade/colonialidade.

Diversalidade, pluriversidade, cosmopolitismo são um horizonte semântico perseguido por Mignolo. No entanto, como alerta Orellana (2015), "pluriversidade e saber paradigmático são dois assuntos dificilmente compatíveis" (Orellana, 2015, p. 7), pois a ideia de paradigma evoca convergência, o compartilhamento de uma matriz disciplinar comum, a tradição de investigação e questionamentos sobre o mundo. Esse é um paradoxo enfraquecedor da pertinência de um paradigma outro que encapsula a pluriversalidade num "exotismo romântico da alteridade" (Grosfoguel, 2013, p. 44), fixando-a numa virtuosidade ilusória. Alerta Grosfoguel:

O pluriversalismo em lugar do universalismo não é equivalente a um relativismo onde tudo vale. Não é tampouco um 'populismo epistêmico'. 0 pluriversalismo é um conhecimento que toma como ponto de partida o pensamento crítico (não qualquer pensamento) de uma diversidade de tradições epistêmicas e que tem como critério para distinguir ou qualificar como pensamento crítico o anti-capitalismo, anti-imperialismo, anti-eurocentrismo, anti-colonialismo. Sob esse critério, por exemplo, se eu não sou muçulmano e vou estabelecer um diálogo inter-epistêmico com o mundo muçulmano, eu dialogo com as feministas islâmicas e não com Osama bin Laden ou Al-Qaeda" (Grosfoguel, 2013, p. 45).

De acordo com o autor, é preciso um critério de "universalismo negativo" (Grosfoguel, 2013) que permita distinguir pensamento hegemônico eurocêntrico e 
pensamento crítico dentro de uma mesma subalternidade, como no caso do islamismo (p. 44).

Seguindo a lógica do argumento de Grosfoguel, a ideia paradigmática de Mignolo se fragiliza porque sugere uma "convergência da pluriversidade" como se esta fosse genuinamente virtuosa, e não das negações das opressões compartilhadas, comuns. Afinal, são os padrões opressores o que promove o apagamento da pluriversalidade crítica. Ao contrário do que Mignolo propõe, convergir a partir da negação do sofrimento comum é o que alimenta as insurgências das diversas identidades políticas que conjuram seus "universalismos negativos", os quais, por sua vez, só dialogam na dimensão da estratégia, da ação, da luta (universalismos negativos do patriarcado, do racismo, da homofobia, da xenofobia, da misoginia, etc); e, ainda assim, não se pode perder de vista que as soluções apontadas por estas diversas ações e lutas serão, "no máximo, similares" em termo de objetivos, como adverte Grosfoguel (2013), "mas institucionalmente distintas" (Grosfoguel, 2013, p. 45), devido às diferentes contingências históricas da multiplicidade epistemológica existente no mundo.

Sendo assim, em vez de um "paradigma outro", convergente da pluriversidade, sem levar em conta, claramente, a criticidade, faz mais sentido falar em "universalismos negativos" contingentes, dinâmicos, no plural. Acreditamos que esse veio, o da convergência pela negação, tem uma dimensão política mais coerente com a opção decolonial, que é o ideário da libertação, sendo mais fértil para a insurgência das lutas.

\section{Críticas a partir de Lentes "Mestizas"}

Por fim, para uma advertência mais aprofundada sobre as implicações das concepções de Mignolo sobre o projeto decolonial, trazemos aqui algumas críticas da acadêmica e militante assumidamente mestiza, de origem aymara e europeia, Silvia Rivera Cusicanqui, socióloga e professora emérita da Universidad Mayor San Andrés, na Bolívia. Rivera Cusicanqui acusa Mignolo de defender um conceito monolítico de cultura fronteiriça, "divorciado da realidade cultural concreta, de sua particular dispersão, mistura e heterogeneidade" (apud Orellana, 2015, p. 16). Assim, nem pensamento fronteiriço, nem paradigma outro corresponderiam “às realidades concretas da 
marginalidade nas sociedades latinoamericanas, suas formas de mobilização, luta e resistência das massas" (p. 16).

0 que a autora alerta é que os efeitos do reducionismo racial e culturalista, aos quais Mignolo acaba não escapando, "excluem enormes setores da população marginal e empobrecida, que nem sempre estão marcados racialmente como índios ou negros" (Restrepo e Rojas, 2010, p. 2019 apud Orellana, 2015, p. 16), ou como portadores de uma cultural ancestral que precisa ser "restituída" no pensamento fronteiriço e fixada no paradigma outro, mas como "consumidores e reprodutores da cultura de massas contemporânea" (p. 16).

A dicotomização de Mignolo entre o que é genuinamente subalterno ou eurocêntrico, rejeitando como ação ou luta descolonizadora tudo o que é "contaminado" pela perspectiva moderna, é, na verdade, segundo a autora, "um discurso neutralizador das práticas descolonizantes, ao entronizar na academia o limitado e ilusório reino da discussão sobre modernidade e descolonização" (Cusicanqui, 2010, p. 68-69). Portanto, Rivera Cusicanqui ao atacar a própria matriz de pensamento modernidade/decolonialidade, denuncia o insatisfatório aparato analítico de Mignolo para se compreender "as lógicas efetivas da exclusão contemporânea em uma escala mundial" (apud Orellana, 2015, p. 16).

Sob essa perspectiva da autora, a forma como a modernidade é fixada no lado opressor, como se fosse um campo monolítico e pausterizador da pluriversidade, acaba promovendo a distância e mesmo a ruptura do pensamento decolonial com as forças sociais insurgentes (Cusicanqui, 2010, p. 58), edificando, consequentemente, classificações essencializadoras.

O discurso de Mignolo, de acordo com a crítica severa de Cusicanqui, estaria no rol do "discurso miserabilista da memória étnica" (2010). Assim, de acordo com a autora, a interpretação dicotômica e simplista da díade modernidade/colonialidade apaga as lutas derivadas diretamente das contingências performáticas das estruturas de dominação, como o racismo e o sexismo. A modernidade, então, seria a própria contingência, inescapável, porém não monolítica. “O índio é parte da modernidade, não é uma tradição estagnada, estática e petrificada, mas uma dinâmica de interações conflitivas contenciosas com poderes coloniais de diferentes escalas" (Cusicanqui, 2012), adverte a autora. 
Ela denuncia que concepções como as de Mignolo negam a coetaneidade das populações indígenas e as aparta das lides da modernidade, como se dela, estas não fizessem parte. "Não se pode entrar e sair da modernidade como se estivesse num tribunal ou num teatro", alerta a autora (Cusicanqui, 2010, p. 71). Ainda de acordo com Cusicanqui, cujo ponto de vista parte do contexto boliviano, existe uma aposta "índia" pela modernidade, que se centra em uma noção de cidadania que não busca a homogeneidade, mas a diferença (p. 71):

La modernidad que emerge de estos tratos abigarrados y lenguajes complejos y mezclados es lo que construye la hegemonía india al realizarse en los espacios creados por la cultura invasora - el mercado, el estado, el sindicato. Al hacerlo, se funda un proyecto de modernidad más orgánica y propia que la modernidad impostada de las elites, caricaturas de occidente que viven de la ventriloquía de conceptos y teorías, de corrientes académicas y visiones del mundo copiadas del norte o tributarias de los centros de poder hegemónicos (Cusicanqui, 2010, p. 73).

A subversão, na perspectiva de Rivera Cusicanqui, parece ser uma saída-chave para a sobrevivência dos sujeitos subalternizados, que não estariam imbuídos necessariamente de virtuosidade, nem se involucrariam numa restituição de cosmogonias e cosmologias originárias, como parece apostar alguns autores decoloniais (Mignolo, Quijano, etc) como projeto de descolonização, mas estariam para o que Hall (2006) chamou de "rotas negociadas".

Dessa forma, a autora elabora uma proposta de interpretação e de ação política a partir de uma identidade $c h^{\prime} i x i$ :

La noción de ch'ixi,..., equivale a la de "sociedad abigarrada" de Zavaleta4, y plantea la coexistencia en paralelo de múltiples diferencias culturales que no se funden, sino que antagonizan o se complementan. Cada una se reproduce a sí misma desde la profundidad del pasado y se relaciona con las otras de forma contenciosa (Cusicanqui, 2010, p.71).

A descolonização ${ }^{5}$ em Rivera Cusicanqui, diferentemente de um pluriversalismo encapsulado num ideal virtuoso, distanciado das experiências verdadeiramente encarnadas da subalternidade, se baseia na "possibilidade de uma convivência

\footnotetext{
4 De acordo com Antezana (1991), o conceito de "formação social abigarrada" elaborado pelo sociólogo boliviano René Zavaleta Mercado está intimamente ligado às reflexões do autor sobre a democracia como um "processo de autodeterminação da massa" (Antezana, 1991, p. 117).

${ }^{5}$ Uso esse termo pelo motivo de a própria autora ser crítica à origem do termo "decolonial". Cusicanqui se alinha à visão de Casanova. Para ela é mais pertinente falar em "colonialismo interno" do que em "colonialidade".
} 
abigarrada", que "não hibridiza mediando as distâncias, mas reconhece o conflito que a diferença irresolúvel comporta e o subverte em potência" (Tarrés, 2009, p. 8).

\section{Amefricanidade e Quilombo: Lugares de Ação e Ressignificação da Existência}

Após a advertência sobre o risco de as concepções um paradigma outro e pensamento fronteiriço, formulados por Walter Mignolo, culminarem em um paradoxo com o próprio projeto decolonial, obliterando a visibilidade das lutas cotidianas por libertação, pretendemos, a partir de agora, argumentar sobre a potência decolonizadora em categorias forjadas nos pensamentos das intelectuais afrolatinoamericanas, Lélia Gonzalez e Beatriz Nascimento; categorias, estas, que perfazem um caminho reflexivo e ativo, alternativo às proposições de Mignolo, e que merecem ser retomadas e (re)introduzidas de forma mais significativa nos debates sobre projetos intelectuais emancipatórios da região.

6.1 Amefricanidade. No desenvolvimento da categoria de amefricanidade, Lélia Gonzalez retomou a ideia dos psicanalistas lacanianos brasileiros, Betty Milan e M. D. Magno (1981 apud Gonzalez, 1988), que questionavam a sobreposição da latinidade da "América Latina" frente as ressignificações resistentes das africanidades oriundas dos povos racializados e escravizados, arrancados do continente africano. Tomando o caso do Brasil, seria preciso atentar, segundo essa ideia, para o fato de que as formações do inconsciente desse país estão longe de serem exclusivamente europeias, brancas. Ao invés disso, o Brasil, na verdade, estaria mais para uma "América Africana”, com história e características societárias cuja nomeação mais coerente seria Améfrica Ladina (Gonzalez, 1988, p. 69), um termo, cujo jogo semântico traduziria a sintomática brasileira. Todos os brasileiros, para Lélia Gonzalez, seriam ladinoamefricanos - não somente os "pretos" e "pardos" categorizados pelo IBGE. No entanto, a rejeição da presença arquetípica afroameríndia expressaria a neurose cultural brasileira: o racismo, tipificado por Gonzalez, no caso brasileiro, como racismo por denegação. Ela transporta a categoria freudiana de denegação (Verneinung) para conceituar o racismo "à brasileira", que se volta "contra aqueles que são testemunhos vivos da mesma (os negros), ao mesmo tempo que 
diz não o fazer" (Gonzalez, 1988, p. 69). A ideologia da "democracia racial", para a autora, seria o maior exemplo dessa negação neurótica.

É importante ressaltar que, assim como outros autores da perspectiva afrocêntrica, antes mesmo da construção da expressão mais conhecida do projeto decolonial colonialidade do poder, cunhada por Aníbal Quijano no início da década de 1990 -, Lélia Gonzalez e Beatriz Nascimento (assim como outros autores e autoras negros e negras, a exemplo de Guerreiro Ramos e Abdias Nascimento) já localizavam o racismo como o eixo primordialmente estruturante do sistema capitalista e suas investidas coloniais e imperiais. E mesmo antes das discussões sobre opressão interseccional serem difundidas a partir de Kimberlé Crenshaw, desde a década de 1980, as duas autoras brasileiras e mais acentuadamente Gonzalez, já se referiam à mulher negra como o centro, por excelência, da opressão derivada da articulação de diversas estruturas de poder fundantes do colonialismo, entre elas as visibilizadas pelas categorias de raça, classe, sexo e poder. No entanto, diferentemente do modo analítico de esquartejamento das categorias de opressão, Gonzalez e Nascimento, ao meu modo de ver, colocam o racismo como o hipocentro das hierarquias opressoras. Com essa forma de interpretar, pode-se dizer que o exercício do patriarcado na colonialidade só se dá derivado do racismo.

Claudia Pons Cardoso (2014) identificou primorosamente nas ideias de Lélia Gonzalez uma interpretação adiantada da autora sobre o que María Lugones $(2008,2011)$ viria a argumentar na sua tese decolonial sobre a colonialidade de gênero, ao questionar o vazio explicativo deixado por Aníbal Quijano sobre as raízes do sistema binário de gênero no conceito de colonialidade do poder. Tensionando e enriquecendo a ideia quijaniana de colonialidade do poder, Lugones propõe, então, o conceito de sistema moderno/colonial de gênero, o qual a autora acredita ser capaz de desvelar a lógica opressiva da modernidade colonial e a "extensão e profundidade histórica de seu alcance destrutivo". 0 corpo, o sexo e o próprio gênero, de acordo com Lugones, foram construídos "racializadamente" (2008, p. 77 apud Cardoso, 2014, p. 970). A conexão das ideias de Lugones às de Lélia Gonzalez pode ser feita a partir da crítica que a segunda autora faz à tese de Simone de Beauvoir:

[...] quando esta [Simone de Beauvoir] afirma que a gente não nasce mulher, mas que a gente se torna (costumo retomar essa linha de pensamento no sentido da questão racial: a gente nasce preta, mulata, parda, marrom, roxinha, etc., mas tornar-se negra é uma conquista). Se a gente não nasce mulher, é porque a gente nasce fêmea, de acordo com a 
tradição ideológica supracitada: afinal, essa tradição tem muito a ver com os valores ocidentais (Gonzalez, 1988d apud Cardoso, 2014, p. 973).

As autoras, portanto, em tempos distintos, pontuam a destituição do status de humanidade à mulher negra pelo sistema de opressão derivado do colonialismo ${ }^{6}$. Nessa perspectiva, mulher seria uma categoria atribuída pelo imaginário eurocêntrico-racialpatriarcal às mulheres brancas, de origem europeia. Às mulheres racializadas como "negras" ou "índias", caberia o status de "animal sem razão".

0 racismo, portanto, desencadeador das "feridas coloniais", será a própria contingência do que autora cunhou como amefricanidade. Ela ainda distingue duas "faces" do racismo, que a despeito de se diferenciarem enquanto "táticas" têm o mesmo objetivo: a "exploração/opressão" (1988, p. 72). O primeiro tipo, o racismo aberto, seria característico das colonizações protagonizadas por sociedades de origem anglo-saxônica, germânica ou holandesa, cuja articulação ideológica aloca o signo "negro" à ascendência, ou seja, "negra é a pessoa que tem sangue negro nas veias" (Gonzalez, 1988, p. 72). Essa face do racismo não tolera a miscigenação, apesar de, como bem lembra a autora, o estupro e a exploração sexual da mulher negra terem sido sempre um fato. No entanto, a expressão desse racismo ganha uma institucionalidade objetiva, segregadora dos grupos não-brancos, como foi a doutrina do apartheid, na África do Sul.

Já as colonizações protagonizadas por sociedades de origem latina, notadamente as luso-espanholas, originaram um tipo de racismo por denegação ou disfarçado, sustentado pela ideologia produtora das "teorias" da miscigenação, da assimilação e da democracia racial (p. 72). Esse é o padrão que prevalece na América Latina e, ao olhar de Lélia Gonzalez, se constitui na forma mais sofisticada de alienação dos sujeitos racializados.

Para compreender os fundamentos desse tipo de racismo, Lélia Gonzalez recorre à formação histórica dos países ibéricos7, rememorando a "sólida experiência quanto aos

\footnotetext{
${ }^{6}$ Podemos ainda identificar uma convergência entre o que Gonzalez e Lugones dizem com a problemática exposta por Soujorner Truth, proferido em 1851 na Women's Convention em Ohio: “Aqueles homens ali dizem que as mulheres precisam de ajuda para subir em carruagens, e devem ser carregadas para atravessar valas, e que merecem o melhor lugar onde quer que estejam. Ninguém jamais me ajudou a subir em carruagens, ou a saltar sobre poças de lama, e nunca me ofereceram melhor lugar algum! E não sou uma mulher?". In.: CARNEIRO, Sueli. Sobrevivente, testemunha, porta-voz. Entrevistada por Bianca Santana. Revista Cult, no 223. São Paulo, maio de 2017.

${ }^{7}$ A autora se sintoniza de forma tempestiva, na década de 1980, com as lentes de Wayne Chandler (1987), que reposiciona a presença africana na história da civilização ocidental através do protagonismo "mouro",
} 
processos mais eficazes de articulação das relações raciais” (Gonzalez, 1988, p. 73) que Portugal e Espanha adquiriram no processo de "Reconquista", contra a presença moura e árabe na Ibéria (ou Al-Andulus), iniciada em 711, com a ocupação berbere, perdurando na península por quase oito séculos, até os governos das dinastias dos Almorávidas e dos Almóhadas, procedentes da África Ocidental. A despeito das profundas marcas "raciais" e civilizacionais da presença moura na Ibéria, o processo da "Reconquista" organizou uma forma de dominação do território fundamentada na hierarquização e dominação racial. Lélia Gonzalez pontua as especificidades desse tipo de racismo, manifesto, por consequência da colonização, na América Latina:

Enquanto grupos étnicos diferentes e dominados, mouros e judeus eram sujeitos a violento controle social e político. As sociedades que vieram a constituir a chamada América Latina foram as herdeiras históricas das ideologias de classificação social (racial e sexual) e das técnicas jurídicoadministrativas das metrópoles ibéricas. Racialmente estratificadas, dispensaram formas abertas de segregação, uma vez que as hierarquias garantem a superioridade dos brancos enquanto grupo dominante. [...] 0 racismo latinoamericano é suficientemente sofisticado para manter negros e índios na condição de segmentos subordinados no interior das classes mais exploradas, graças à sua forma ideológica mais eficaz: a ideologia do branqueamento (Gonzalez, 1988, p. 73).

Após uma breve mostra da caracterização das opressões raciais derivadas de duas grandes matrizes coloniais, elaborada por Gonzalez, é preciso destacar agora a força epistêmica da categoria amefricanidade: ela está na costura de um lugar comum das reações, resistências e lutas insurgidas da contingência dessas duas formas de racismo, quebrando, inclusive, a reprodução imperialista da adjetivação afro-american (afroamericano) ou african-american (africano-americano). Gonzalez fez a aposta de que

as implicações políticas e culturais da categoria de Amefricanidade (amefricanity) são, de fato, democráticas; exatamente porque o próprio termo nos permite ultrapassar as limitações de caráter territorial, linguístico e ideológico, abrindo novas perspectivas para um entendimento mais profundo dessa parte do mundo onde ela se manifesta: A AMÉRICA e como um todo (Sul, Central, Norte e Insular) (Gonzalez, 1988, p. 76).

Amefricanidade, portanto, é uma categoria que possibilita a evidência de uma unidade específica, como explica a própria autora, "forjada no interior de diferentes sociedades que se formaram numa determinada parte do mundo" (Gonzalez, 1988, p. 77),

adjetivo racializado por conta de sua a origem negra, e de Martin Bernal e seu trabalho seminal Black Athena (1987), onde o autor remonta a África na origem da cultura grega. 
em que se engendra continuamente um processo histórico de "intensa dinâmica cultural (adaptação, resistência, reinterpretação e criação de novas formas) que é afrocentrada (p. 76). Essa unidade específica ou esse lugar comum é o sistema etnográfico de referência o qual Lélia Gonzalez chamou de Améfrica. Podemos dizer hoje que esse sistema etnográfico pensado por Gonzalez é um dos lados do Atlântico Negro de Gilroy (2001), em que está em plena circulação, "idéias, ativistas, artefatos culturais e políticos" (Gilroy, 2001, p.38). Ao contrário das categorias essencializadoras, a amefricanidade se origina da tensão provocada à condição estrutural do racismo pela tese existencial da contingência, portanto, edifica uma força epistêmica engendrada da própria ação dos sujeitos racializados, que compartilham consciente e inconscientemente a ferida do racismo.

Temos, desta forma, a amefricanidade como uma vertente rica epistemicamente para compreendermos as insurgências de novas ou renovadas construções sociais e políticas, levando a cabo o desejo fanoniano de "transformar o negro em um ser de ação" (Gordon, 2008, p. 15). Quilombos, cimarrones, cumbes, palenques, marronages e maroon soieties $^{8}$, desde a escravidão institucionalizada, por toda a "América", já eram expressões de amefricanidade, como frisou Gonzalez (1988, p. 79), assim como é amefricana a subversão das mulheres a quem foi atribuída a figura da "mãe preta", a "bá" que, ao contrário do "exemplo extraordinário de amor e dedicação totais como querem os brancos e nem tampouco essa entreguista, essa traidora da raça como querem alguns negros muito apressados em seu julgamento", ela exerceu, na verdade, a própria "função materna" (Gonzalez, 1984, p. 236), passando

todos os valores que lhe diziam respeito prá criança brasileira, como diz Caio Prado Júnior. Essa criança, esse infans, é a dita cultura brasileira, cuja língua é o pretuguês. A função materna diz respeito à internalização de valores, ao ensino da língua materna e a uma série de outras coisas mais que vão fazer parte do imaginário da gente (Gonzalez, 1979c). Ela passa prá gente esse mundo de coisas que a gente vai chamar de linguagem. E graças a ela, ao que ela passa, a gente entra na ordem da cultura, exatamente porque é ela quem nomeia o pai (Gonzalez, 1984, p. 236)

Essa narrativa ficcional do etnocentrismo branco da "mãe preta" como a figura simpática, amorosa e inofensiva, "dissimulando, inclusive, os horrores do período escravista para as mulheres negras escravizadas e/ou libertas", como arremata Cardoso

\footnotetext{
8 Esses são nomes que se convencioram a chamar as insurgências contra a escravidão em diversas sociedades originadas do colonialismo na América e onde se pode identificar estratégias de resistência com base em "formas alternativas de organização social livre" (Gonzalez, 1988, p. 79).
} 
(2014, p. 976), tem, na verdade, a função de negar a ação das mulheres negras, a sua existência histórica. No entanto, Lélia Gonzalez recupera a "mãe preta" como sujeita política (Cardoso, 2014, p. 976), evidenciando como as mulheres "vestidas" por essas lentes da colonialidade subverteram, da forma que puderam, e até onde puderam, consciente ou inconscientemente, a ordem opressora, simplesmente desenvolvendo suas formas de sobrevivência e existência histórica, inserindo suas próprias narrativas e categorias de matriz "negro-africanas" na formação dos valores e das crenças da sociedade brasileira (p. 976).

Foi por aí que ela [a "mãe preta] africanizou o português falado no Brasil (transformando-o em 'pretuguês') e, conseqüentemente, a cultura brasileira. Lélia Gonzalez, ao valorizar a resistência desenvolvida pela "mãe preta", no período escravista, muitas vezes, realizada através da negociação, assegurando com a ação sua sobrevivência, a de sua prole e a de seus parceiros, evidencia o movimento do sujeito resistindo à objetificação que lhe é imposta. Dito em outras palavras, a autora ilumina as estratégias desenvolvidas pelas mulheres negras escravizadas para enfrentar o processo de dominação/exploração que procurava mantê-las como outro/escravo/objeto (Cardoso, 2014, p. 976).

Ainda podemos pensar como formas de amefricanidade, entre inúmeras, as irmandades leigas de negros emergidas no período colonial, algumas sobrevivendo e atualizando suas existências, como na Bahia e em Minas Gerais; as missas da Igreja Rosário dos Pretos, na Bahia, em que os atabaques sagrados do candomblé, Rum, Rumpi e Lé, integram a liturgia falada em latim, português e yorubá; os Congados e Reizados; a batida das cordas da guitarra e do baixo no blues no lugar dos tambores (antes, proibidos); a fratura que o jazz provocou na estrutura compartimentada da música; o hip hop; os afoxés; as reinvenções e invenções de africanidades; os quilombos contemporâneos e as etnogênses indígenas. Em tudo isso, consigo enxergar a ação amefricana nas suas atualizações, nas negociações das rotas (Hall, 2003) que os marcados pela ferida do racismo tiveram de empreender. Reconhecer essa categoria, como defende Lélia Gonzalez, é reconhecer "o gigantesco trabalho de dinâmica cultural"- (e eu acrescentaria: trabalho de dinâmica política) - "que não nos leva para o lado do Atlântico, mas que nos traz de lá e nos transforma no que somos hoje: amefricanos" (Gonzalez, 1988, p. 79).

No entanto, algumas perguntas que deixo aqui, e que tentarei explorar em outros espaços de interlocução acadêmica e militante, é: o que faz com que toda essa expressão amefricana seja majoritariamente reconhecida somente no espectro seccionado da 
"cultura"? Como enxergar a subversão amefricana no jogo inexorável para a sobrevivência, que é o jogo com os poderes instituídos e formatadores do Estado?

6.2 Quilombo ontem e hoje. Uma outra categoria que trazemos aqui é a de quilombo, da historiadora, pesquisadora e ativista Beatriz Nascimento, cunhada na sua investigação "prolongada e exaustiva"9 (Nascimento, 1982, p. 259) sobre quilombo intimamente harmônica com a categoria de amefricanidade. 0 projeto nomeado pela autora de Sistemas alternativos organizados pelos negros - dos quilombos às favelas ${ }^{10}$, inaugura uma forma de compreensão de quilombo que transgride a fixação de seu sentido ao sistema escravagista colonial e imperial. A autora procurou demonstrar que "os homens e seus grupamentos, que formaram no passado o que se convencionou chamar 'quilombos', ainda podem e procuram fazê-los" (Nascimento, 1982, p. 259), sem se tratar necessariamente de "sobrevivências" ou "resistência cultural", mas de expressões concretas de uma continuidade histórica, cujo sentido em seu trajeto metodológicoinvestigativo, diferentemente das construções lineares da história e da historiografia moderna, ganha a qualidade de "aberta", em que se torna possível a ressignificação do passado e a implosão das narrativas dos “vencedores”. Está aí, portanto, a conexão íntima da concepção de quilombo de Beatriz Nascimento com a categoria de amefricanidade.

Um dos enquadramentos da contribuição de Beatriz Nascimento que quero destacar aqui, é o de quilombos como "territórios de liberdade", como bem interpreta Ratts (2009). Estabelecendo uma relação crítica à documentação existente, por ser produto de narrativas dos repressores (brancos), Beatriz Nascimento escava outras fontes para uma ressignificação histórica e abertura de possibilidades futuras. Ao comparar tipologicamente diversos quilombos no Brasil e em Angola (região de onde veio a maior parte dos sujeitos racializados e escravizados na diáspora forçada), ela chega à conclusão de que "na raiz de todos os quilombos, existe uma procura espacial do homem que se relaciona com muitas questões discutidas atualmente, como a ecologia" (Nascimento,

\footnotetext{
9 É preciso externar aqui o pesar sobre a interrupção do protagonismo de Beatriz do Nascimento: o seu desbravamento sobre o tema quilombo na academia foi estancado pela misoginia e racismo, e o legado de sua reconceitualização de quilombo apagado pelo racismo e patriarcado acadêmico. Beatriz do Nascimento foi assassinada em 1995, no Rio de Janeiro, ao defender uma amiga de seu companheiro violento. Sua morte trágica está entre outras na perpetuação da tragédia que acomete as mulheres negras desde que seus corpos foram racializados e objetificados pelo colonialismo.

10 A despeito de ser um longo projeto, inacabado, esse foi o nome dado por Beatriz Nascimento ao seu trabalho de conclusão da pós-graduação lato sensu em História, na Universidade Federal Fluminense (UFF), em 1981.
} 
1981 apud Ratts, 2009, p. 59); procura, esta, que se revela em uma ação contínua, irrefreável. Como interpreta Ratts (2009), quando a autora amplia a concepção de quilombo para uma vertente além da concepção histórica, "ela estende seu significado para abranger um território de liberdade, não apenas referente a uma fuga, mas uma busca de um tempo/espaço de paz" (Ratts, 2009, p. 59). Em consequência, Nascimento transmigra para o espaço acadêmico, que é um espaço de poder, uma noção de território distinta da noção moderna culminada na ideia de Estado-nação e engessada pelos princípios liberais. Ela apresenta um sentido de território que atravessa o espaço geográfico e o submete à subjetividade coletiva, atrelando a existência ao acesso pleno ao território, que vai do próprio corpo à territorialidade físico-espacial. Essa ideia pode ser compreendida na sua escrita:

Várias e várias partes da minha história contam que eu tenho o direito ao espaço que ocupo na nação. E é isso que Palmares vem revelando nesse momento. Eu tenho o direito ao espaço que ocupo dentro desse sistema, dentro dessa nação, dentro desse nicho geográfico, dessa serra de Pernambuco. (...) Meu espaço é o meu quilombo. Onde eu estou, eu estou. Quando eu estou, eu sou" (1989 apud Ratts, 2009, p. 59).

Sem sombras de dúvidas, a investigação e reconstituição feitas por Beatriz Nascimento do "sentido" do que se convencionou "quilombo", desde o empreendimento escravista colonial até o século XX, impactou profundamente nas ressemantizações desse conceito e cuja repercussão é crucial para a luta quilombola contemporânea. Podemos, por exemplo, encontrar o "sentido" escavado por Beatriz Nascimento compondo o repertório das trincheiras quilombolas na batalha institucional pelo direito à existência $\mathrm{e}$ ao território, a exemplo da luta contra a Ação Direta de Inconstitucionalidade (ADI) no 3239, impetrada pela bancada ruralista através do antigo PFL e sustentada pelo DEM. Sentido, este, que, a despeito das batalhas institucionais, tensiona, ao mesmo tempo, os fundamentos do modelo estatal vigente. Quilombo, em Beatriz Nascimento, pode, portanto, ser visto como uma ação amefricana, porque, desde sua origem, é inclusiva de diversos setores subalternos/racializados, cujas atualizações estão atreladas às respostas contras as atualizações da colonialidade. O negro, como destaca a autora, não estava limitado à história da fazenda ou da escravidão. Mais do que isso, Beatriz Nascimento evidencia o sujeito histórico negro como protagonista da história de luta pela libertação, de construção da liberdade (para além da liberdade liberal), eivada de significados oriundos de cosmogonias outras, que não a europeia. 


\section{Considerações Finais}

Ao nos voltarmos criticamente sobre as concepções de pensamento fronteiriço e paradigma outro elaboradas por Walter Mignolo, a partir de pistas já escavadas por alguns autores (Grosfoguel, 2003, 2013; Cusicanqui, 2010; Walsh, 2005), é possível perceber um défict decolonial arrefecedor das ações descolonizadoras, justamente por estas concepções conterem imprecisões e contradições como dispositivo analítico e como projeto epistêmico. Isso pôde ser flagrado ao tensionarmos as ideias de pensamento fronteiriço e de paradigma outro, com as propostas de posicionamento crítico fronteiriço de Walsh (2005), de universalismo negativo de Grosfoguel (2003) e de identidade ch'ixi de Rivera Cusicanqui (2010).

Mignolo assume de forma dicotômica e simplista que a superação da colonialidade jamais residiria na modernidade. 0 esteio reflexivo decolonial, na ótica de Mignolo (2003), demarca que "não houve, não há e nunca haverá modernidade sem colonialidade" (Mignolo, 2003, p. 35). Mas, então, se colonialidade e modernidade "são duas faces da mesma moeda" (2003, p. 30), de onde poderia emergir uma ação libertadora dos subalternizados pela colonialidade sem que esta ação não seja afetada, condicionada pela própria modernidade, pela "ferida" que ela imputa?

Um dos desafios explícitos nas formulações de Mignolo é nelas enxergar uma alternativa à inescapabilidade da modernidade. E por essa fragilidade, entendemos que, em vez de somar potência ao projeto decolonial, que tem como último fim a libertação, as concepções de Mignolo produzem constrangimentos às lutas descolonizadoras ao se distanciar das contingências históricas e inexoráveis, atualizações das estruturas de poder e dominação.

Feita uma breve crítica a determinadas vulnerabilidades presentes nas concepções de paradigma outro e pensamento fronteiriço introduzidas no pensamento decolonial por Walter Mignolo, procuramos evidenciar, através da discussão das categorias amefricanidade e quilombo, forjadas respectivamente nos pensamentos das intelectuais afrolatinoamericanas Lélia Gonzalez e Beatriz Nascimento, a necessidade de visibilizar a potência de ação política latente nas performances de resistência e sobrevivência dos 
sujeitos racializados e inseridos na complexa teia das opressões estruturais, atualizadas e orquestradas na contingência histórica pela colonialidade do poder.

Tentei mostrar que estas categorias perfazem um caminho reflexivo e ativo, alternativo a proposições de autoctonia sectárias presentes no pensamento decolonial. Sugeri que as posturas epistêmicas de Lélia Gonzalez e Beatriz Nascimento são reveladoras e instigadoras de processos de ações concretas, que podem enriquecer os caminhos teóricos, de politização e práticos da elaboração da ideia de libertação pelos projetos intelectuais emancipatórios insurgentes na América Latina. Ou seja, acredito que, com as autoras acionadas neste texto, através da vocalização de suas perspectivas de forma situada nas contingências engendradas e derivadas da lógica do colonialismo, podemos enxergar a ação prática de subversão da colonialidade onde determinadas lentes sectárias do projeto decolonial se recusam ou negligenciam em enxergar.

Desta forma, partindo do princípio de que evidenciar a opressão é imprescindível, mas não o suficiente, o caminho que aqui tentei trilhar, sob o exemplo de Lélia Gonzalez e Beatriz do Nascimento, é de contribuir com o descortinamento, valorização e reposicionamento teórico das formas de resistência e luta dos sujeitos submetidos aos horrores do colonialismo e da colonialidade; formas, estas, geradoras de sistemas de autoridade e poderes distintos do Estado. Esse é um passo fundamental para qualquer tentativa de visibilização, nessas ações, de alternativas possíveis de reordenamento civilizatório e estatal.

Sobreviver e existir, num contexto de opressão extrema, de potencial destrutivo não somente da subjetividade, mas dos próprios corpos, já são verbos que estão - para os sujeitos racializados e atacados cotidianamente pelos horrores da colonialidade nas suas mais diversas dimensões opressivas -, inexoravelmente no campo da ação. E essa sobrevivência e existência implicam também persistir em tratar da política considerando a inescapabilidade de suas formas pragmáticas como lembram Burity, Lopes e Mendonça (2015, p. 15), desde na "mecânica da institucionalidade jurídico-política ao dinamismo negociado das políticas públicas".

Por isso apostamos na conexão solidária das categorias de Lélia Gonzalez e Beatriz Nascimento às formulações de Khatibi trazidas a esse texto através de Walsh, as quais se mostram muito mais próximas do sentido radical de luta fanoniana, por atribuir ao 
pensamento a possibilidade real de "decolonializar-se", se transmutando em pensamentoação, justamente por não abandonar a dimensão da estratégia, "uma estratégia sem sistema fechado", que se assuma como "uma construção de um jogo do pensar e do político, que ganha terreno silenciosamente sobre seus desfalecimentos e seus sofrimentos" (apud Walsh, 2005, p. 22).

Amefricanidade e quilombo são categorias que estão mais para a "interculturalização crítica", proposta de Walsh, uma consequência do posicionamento crítico fronteiriço, do que para um pensamento fronteiriço ou um paradigma outro. Estariam mais para a construção de "vínculos estratégicos" para a construção de sobrevivência e existências cujo esteio viabilizador é inexoravelmente a luta, desde suas formas mais comezinhas e subliminares às mais organizadas e pragmáticas.

\section{Referências Bibliográficas}

BURITY, Joanildo A.; LOPES, Alice C., MENDONÇA, Daniel de. (2015), A contribuição da Hegemonia e estratégia socialista para as ciências humanas e sociais. Prefácio à ediçaõ brasileira. In.: LACLAU, Ernesto; MOUFFE, Chantal. Hegemonia e estratégia socialista: por uma política democrática radical. Tradução de Joanildo A. Burity, Josias de Paula Jr. e Aécio Amaral - São Paulo: Intermeios, Brasília, 2015.

CARDOSO, Cláudia P. (2014), Amefricanizando o feminismo: o pensamento de Lélia Gonzalez. Revista Estudos Feministas (UFSC. Impresso) , v. 22, p. 965-986, 2014

CARNEIRO, Sueli. (2017), Sobrevivente, testemunha, porta-voz. Entrevista. Santana, Bianca. Revista Cult, no 223. São Paulo, maio de 2017.

CASANOVA, Pablo G. (2003). Colonialismo Interno (una redefinición). In.: Revista Rebeldía, No. 12, (octubre de 2003):

http://www.revistarebeldia.org/revistas/012/art06.html

CUSICANQUI, Silvia. Rivera. (2010), Ch'ixinakax utxiwa: Reflexión sobre prácticas y discursos descolonizadores. Ediciones Tinta Limón, Buenos Aires: 2010.

DUSSEL, Enrique. (1993). 1492: O encobrimento do outro: A origem do mito da modernidade: Conferências de Frankfurt / Enrique Dussel; tradução: Jaime A Clasen Petrópolis, RJ: 1993.

FANON, Frantz. (2008), Pele negra, máscaras brancas. Salvador: EDUFBA, 2008. v.2) . (2005), Os condenados da terra. Juiz de fora: Ed. UFJF, 2005. (coleção cultura, 
GONZALEZ, Lélia (1984). Racismo e Sexismo na Cultura Brasileira. In: Revista Ciências Sociais Hoje, Anpocs, p. 223-244.

. (1988), A categoria político-cultural da Amefricanidade. Revista Tempo Brasileiro. Rio de Janeiro, 92/93; p. 69-82, jan.-jun.

. (1991), Entrevista ao MNU. Jornal Nacional do Movimento Negro Unificado, n. 19, p. 8-9, maio/junho/julho.

GROSFOGUEL, Ramón. (2013), Hay que tomarse en serio el pensamiento crítico de los colonizados en toda su complejidad. Entrevista realizada por Luis Martínez Andrade.Metapolítica, n 83, octubre - diciembre de 2013.

(2008), Para descolonizar os estudos de economia política e os estudos póscoloniais: Transmodernidade, pensamento de fronteira e colonialidade global. Revista Crítica de Ciências Sociais, 80, Março: 115-147.

GILROY, Paul. (2001), O Atlântico Negro. Modernidade e dupla consciência, São Paulo, Rio de Janeiro, 34/Universidade Cândido Mendes - Centro de Estudos Afro-Asiáticos, 2001.

HALL, Stuart. (2003). Da Diáspora: identidades e mediações culturais. Belo Horizonte: Editora UFMG.

LUGONES, María. (2008), Colonialidad y Género. Tabula Rasa. Bogotá - Colombia, № 9: 73-101, julio-diciembre 2008.

MIGNOLO, Walter D. (2000), Historias locales / diseños globales. Colonialidad, conocimientos subalternos y pensamento fronterizo. Princeton University Press, 2000 (Trad. Ediciones Akal, 2003. Madrid. Tradutoras: Juan María Madariaga y Cristina Vega Solís). 452 pgs.

NASCIMENTO, Beatriz. (1982), Kilombo e Memória comunitária - um estudo de caso. Revista Estudos-Asiáticos. № 6-7. Centro de Estudos Afroasiáticos - CEAA/UCAM, RJ, 259-265 p.

ORÍ (Original)., (1989). Direção: Raquel Gerber. 91 min. DVD. In.: https://www.youtube.com/watch?v=DBxLx8D99b4.

QUIJANO, Anibal. (2005), Colonialidade do poder, eurocentrismo e America Latina. In.: A colonialidade do saber: eurocentrismo e ciências sociais. Perspectivas latino-americanas. Edgardo Lander (org). Colección Sur Sur, CLACSO, Ciudad Autónoma de Buenos Aires, Argentina. setembro 2005. pp.227-278.

RATTS, Alex., (2006). Eu sou atlântica: sobre a trajetória de vida de Beatriz Nascimento. Instituto Kuanza; Imprensa Oficial: São Paulo.

WALSH, Catherine. (2005), (Re) pensamiento crítico y (De)colonialidad. Reflexões Latinoamericanas. Introducción. In C. Walsh (Ed.), Pensamiento crítico y matríz (De)colonial (pp. 12-34). Quito: UASB-Ediciones Abya Yala, 2005, p. 13-35. 